\title{
Políticas Públicas para o financiamento da educação básica: Mapeando pesquisas
}

\section{sobre o Fundeb}

Public Policies for the Financing of Basic Education: Mapping Research on Fundeb

Políticas Públicas para elfinanciamiento de laeducación básica: mapeo de investigaciones sobre

Fundeb

Received: 08/24/2021 | Reviewed: 08/29/2021 | Accept: 09/02/2021 | Published: 09/05/2021

Morgana Brazil Santos

ORCID: https://orcid.org/0000-0003-4164-1448 Universidade Federal do Amazonas, Brasil E-mail: morgabrazil@yahoo.com.br

Silvia Cristina Conde Nogueira

ORCID: https://orcid.org/0000-0001-6800-5615

Universidade Federal do Amazonas, Brasil

E-mail: silviaconde@ufam.edu.br

\begin{abstract}
Resumo
O artigo tem por objetivo analisar as produções acadêmica existentes com a temática do Fundeb e suas contribuições para a melhoria do processo educacional brasileiro. Trata-se de um estudo amparado por pesquisa bibliográfica e documental que se inicia com o direito à educação como política pública, e continua com o estudo das principais fontes para o financiamento da educação básica a partir da Constituição Federal de 1988, seguindo com a revisão de literatura, cujo destaque é o Fundo de Manutenção e Desenvolvimento da Educação Básica e Valorização dos Profissionais da Educação (Fundeb) .Nesse sentido, as discussões iniciam-se pela escolha por fontes da Biblioteca Digital Brasileira de Teses e Dissertações (BDTD), em virtude da notoriedade da reunião de pesquisas das principais universidades do país, a respeito do assunto. As produções nos mostram uma visão geral de como foi o funcionamento do Fundeb até o ano de2020, demonstrando os aspectos que deveriam ser aprimorados no Novo Fundeb. As pesquisas mostram como o Fundeb durante toda a sua vigência se mostrou fundamental para $o$ financiamento da educação básica, mesmo necessitando de alguns ajustes e aprimoramentos.
\end{abstract}

Palavras-chave: Políticas públicas; Fundeb; Financiamento da educação.

\begin{abstract}
The article aims to analyze the existing academic productions with the Fundeb theme and their contributions to the improvement of the Brazilian educational process. This is a study supported by bibliographical and documentary research that begins with the right to education as a public policy, and continues with the study of the main sources for financing basic education from the 1988 Federal Constitution, followed by the review of literature, whose highlight is the Fund for Maintenance and Development of Basic Education and Valorization of Education Professionals (Fundeb). In this sense, discussions begin with the choice of sources from the Brazilian Digital Library of Theses and Dissertations (BDTD), due to the notoriety of the research meeting of the main universities in the country, on the subject. The productions show us an overview of how Fundeb worked until the year 2020, demonstrating the aspects that should be improved in the New Fundeb. Research shows how Fundeb, throughout its duration, has proven to be essential for financing basic education, even though it needs some adjustments and improvements.
\end{abstract}

Keywords: Public policy; Fundeb; Education financing.

\section{Resumen}

El artículo tiene como objetivo analizar las producciones académicas existentes com el tema Fundeb y sus contribuciones al mejoramiento del proceso educativo brasileño. Se trata de um estudio sustentado en una investigación bibliográfica y documental que comienza con el derecho a la educación como política pública, y continua com el estudio de las principales fuentes de financiamiento de la educación básica de la Constitución Federal de 1988, seguido de la revisión de la literatura, cuyo destaque es el Fondo de Mantenimiento y Desarrollo de la Educación Básica y Valorización de los Profesionales de la Educación (Fundeb). En este sentido, las discusiones comienzan com la elección de fuentes de la Biblioteca Digital Brasileña de Tesis y Disertaciones (BDTD), debido a la notoriedade del encuentro de investigación de las principales universidades del país, sobre el tema. Las producciones nos muestran un panorama de como funcionó Fundeb hasta el año 2020, demostrando los aspectos que deben mejorarse em el Nuevo Fundeb. La investigación muestra cómo Fundeb, a lo largo de su duración, ha demostrado ser fundamental para el financiamiento de la educación básica, aun que necessita algunos ajustes y mejoras.

Palabras clave: Políticas públicas; Fundeb; Financiamiento de la educación. 


\section{Introdução}

Este estudo insere-se na linha de pesquisa "Educação, Políticas Públicas e Desenvolvimento Regional”, e concentra suas investigações na perspectiva de agregar conhecimento aos debates sobre o Fundo de Manutenção e Desenvolvimento da Educação Básica e Valorização dos Profissionais da Educação (Fundeb). Nesse sentido, temos como objetivo analisar as produções acadêmica existentes, no período de 2015 a 2020, a fim de observar como elas contribuíram para a melhoria do processo educacional brasileiro. Dessa maneira, a partir da análise das pesquisas realizadas com a temática Fundeb, compreender a efetividade dessa política pública no ensino e na aprendizagem, nas escolas da rede pública de ensino.

Logo, partimos da premissa de que as políticas públicas são construídas a partir de demandas sociais que, historicamente, institucionalizaram-se e foram reconhecidas como direitos (Martins, 2010). Nesse cenário, o financiamento da educação faz parte das políticas públicas para articular e trazer mais dinâmica ao processo de democratização educacional que ao longo do tempo passou por transformações. A esse respeito, inclusive, Adrião e Pinto (2006) afirmam que no Brasil o padrão de qualidade da educação e os recursos mínimos disponibilizados por meio da vinculação constitucional estão diretamente relacionados. Os autores ressaltam que:

Se é indiscutível que a política de vinculação tem sido elemento fundamental para impedir um sucateamento, ainda maior, do sistema público de ensino, pois, nos momentos em que esta vinculação foi retirada, os gastos com educação despencaram, é evidente também que a adoção de tal medida por si só, não garante uma escola de qualidade (p.42).

O tema central do estudo é a política de financiamento da educação básica, a qualidade da educação, a partir da vinculação dos fundos destinados à área educacional, no contexto nacional e regional. Logo, observando os aspectos constitucionais e legais que permeiam o fundo, analisando como as pesquisas apresentam o movimento que lhe dão ou não funcionalidade, bem como avanços e recuos direcionados à efetivação dos direitos sociais adquiridos ao longo da história, através da luta de movimentos sociais.

Em outras palavras, o tema deste estudo justifica-se pela relevância social e acadêmica que, ao longo do processo de implementação e mudanças do Fundeb, reconhece e considera importante a existência de debates sobre políticas públicas de educação para a federação.

Ressaltamos que o princípio constitucional no seu art. 206 já faz referência à garantia de acesso e permanência do aluno na escola em igualdade de condições, para que esse acesso seja efetivado é fundamental o debate sobre o financiamento da educação como parte da política educacional. Rolim (2021, p.56) destaca que o financiamento das políticas educacionais se torna o epicentro das disputas entre o projeto de educação pública de qualidade para todos - único capaz de promover a emancipação humana e a formação para a democracia - e o dos privatistas, que vêem na educação um serviço rentável.

\section{Metodologia}

Quanto ao procedimento metodológico, optou-se por fazer um mapeamento e, posteriormente, uma revisão de literatura sobre o conhecimento produzido na área do financiamento da educação básica. Assim, o estudo foi realizado através da revisão bibliográfica que cerca a literatura sobre o Fundeb no meio acadêmico. Além disso, pesquisamos a produção discente de Mestrado e Doutorado do banco de dados de dissertações e teses da Biblioteca Digital Brasileira de Teses e Dissertações (BDTD),até 30 de junho de 2020.

A pesquisa bibliográfica considerando a classificação proposta por Gil (2002), caracteriza-se, quanto aos meios, com base em material já elaborado, para obter o corpus documental da pesquisa, iniciamos assim, o percurso metodológico com o levantamento de produções já realizadas sobre o financiamento da educação, revisamos a literatura sobre o Fundeb, 
assim como os trabalhos que versam sobre o financiamento da educação brasileira, por meio de livros, artigos, teses, dissertações. Buscou-se estas informações com base em Abdalla (2016); Aquino (2019); Barbosa (2014); Batista (2017); Behring e Bochetti (2009); Caldeira (2016); Cavalcanti (2019); Cury (2018); Ferreira (2018); Freire (2016); Martins (2010); Menezes (2008); Paro (1998); Peroni (2003); Pinto (2019); Rolim (2021); Senna (2014) entre outros.

\section{Resultados}

\subsection{Políticas Públicas: Direito à Educação}

O financiamento da educação é um dos campos de estudo da política educacional, o qual é considerado um meio de realização de uma política pública setorial. Segundo Senna (2010), entendemos que o financiamento da educação pode ser entendido como uma política pública, inclusive com potencial de indução da adoção de outras políticas, como, por exemplo, o aperfeiçoamento do controle social. Para fundamentação dessa posição é importante trabalhar o conceito de políticas públicas. Isto é, trouxemos o conceito criado por Bobbio (2004), a fim de que isto esteja em esclarecido:

A existência de um direito, seja em sentido forte ou fraco, implica sempre a existência de um sistema normativo, onde por 'existência'deve entender-se tanto o mero fator exterior de um direito histórico ou vigente quanto o reconhecimento de um conjunto de normas como guia da própria ação. A figura do direito tem como correlato a figura da obrigação (p. 38).

Ademais, Cury (2002) corrobora tal premissa afirmando que o contorno legal das políticas públicas indica as regras com seus, com os direitos, os deveres, as proibições, as possibilidades e os limites de atuação. Em suma, possuem enorme impacto no cotidiano das pessoas, mesmo que nem sempre elas estejam conscientes de todas as suas implicações e consequências.

A esse respeito, percebemos que Bonafont (2004 apud, 2010, p. 498) entende política pública como um "conjunto de ações que leva acabo um governo para alcançar um objetivo em relação a um problema de conflito social” , de um lado. De outro, vale ressaltar que Hofling (2001) diferencia Estado e governo, em que o primeiro é o conjunto de instituições permanentes como os órgãos legislativos, as quais possibilitam a ação do governo. O último, conjunto de programas e projetos que faz parte da sociedade organizada e propõe para a sociedade como o todo. A autora ratifica que as políticas públicas são as ações do Estado. Nas palavras dela: “É o Estado implantando um projeto de governo, através de programas, de ações voltadas para setores específicos da sociedade" (p.31).

Segundo Hofling (2001, p.31) "E políticas sociais se referem a ações que determinam o padrão de proteção social implementado pelo Estado, voltadas, em princípio, para a redistribuição dos benefícios sociais visando a diminuição das desigualdades estruturais produzidas pelo desenvolvimento socioeconômico".

Logo, interpretamos que as políticas sociais deveriam fazer parte da ação governamental direcionada ao interesse do povo para diminuição das desigualdades sociais e, portanto, deveriam ser ações planejadas, coletivamente, visando o desenvolvimento, principalmente, das camadas menos favorecidas. Em outros termos, Souza (2006) pondera que, de maneira geral, os conceitos usados para definição de políticas públicas são aqueles que definem tais políticas como ações do governo.

Diante desse cenário, observamos que Piana (2009) ressalta que as políticas sociais surgiram como resposta à Revolução Industrial e suas demandas de desigualdades sociais, sindicalização, urbanização, cooperativismo etc. Dessa forma, as lutas sociais e as mobilizações operárias no século XIX foram a demarcação da gênese da política social, porém não há uma data de fato que concretize esse surgimento, segundo a autora. Com efeito, a política social surge no capitalismo com as mobilizações operárias e a partir do século XIX, com o surgimento de movimentos populares, sendo ela compreendida como estratégia governamental. 
Segundo Piana (2009), para a formulação, acesso e qualidade da educação são necessários para viabiliza os recursos financeiros e financiamentos que atendam à demanda da população e às responsabilidades do poder público, sendo esta uma tarefa árdua. A autora também afirma a necessidade de haver gestão financeira, com instrumentos que assegurem a transparência e democratização das políticas sociais.

A respeito da gestão financeira e universalização dos direitos, percebemos pelos apontamentos de Behring \& Boschetti (2009) que:

\begin{abstract}
A sustentação financeira com possibilidade de ampliação e universalização dos direitos, assim, não será alcançada com ajustes fiscais que expropriam recursos das políticas sociais. A consolidação da seguridade social brasileira, e da política social brasileira de uma forma geral, já que essa direção atinge também políticas que estão dentro do orçamento fiscal, depende da reestruturação do modelo econômico, com investimentos no crescimento da economia, geração de empregos estáveis com carteira de trabalho, fortalecimento das relações formais de trabalho, redução do desemprego, forte combate à precarização, transformação das relações de trabalho flexibilizadas em relações de trabalho estáveis, o que, consequentemente, produzirá ampliação de contribuições e das receitas da seguridade social e, sobretudo, acesso aos direitos sociais (p.172).
\end{abstract}

Assim, as políticas sociais devem estar voltadas ao combate à desigualdade social, como também à garantia dos direitos sociais dos trabalhadores, sendo necessária sua ampliação para que mais brasileiros tenham assegurados sua dignidade humana, isto com qualidade de vida e condições de trabalho favoráveis.

Nesse contexto, compreendemos que, no mundo contemporâneo, a cidadania enfrenta vários desafios, como novos espaços de atuação, buscando transformações que garantam um futuro melhor para todos os cidadãos. Em outras palavras, cidadania é a capacidade conquistada por alguns ou todos indivíduos de se apropriarem dos bens socialmente criados, de atualizarem todas as potencialidades de realização humana, abertas pela vida social em cada contexto historicamente determinado (Coutinho, 1999).

Desse modo, quando se fala em cidadania e direitos sociais é importante ressaltar que eles não são direitos naturais, e sim resultados de lutas permanentes. Isto é, nos apontamentos de Coutinho (1999), entendemos que se trata de lutas geralmente travadas a partir das classes dominadas.

A esse respeito, inclusive, Cury (2002) afirma que a educação escolar é uma dimensão fundante da cidadania, e tal princípio é indispensável para políticas que visam à participação de todos nos espaços sociais e políticos, ou seja, para reinserção no mundo profissional. O autor também ressalta que um dos resultados dessas lutas pela igualdade de oportunidades ou mesmo a igualdade de condições sociais, foi a educação escolar além do ensino primário.

Com efeito, o direito à educação pública, universal, gratuita e laica, segundo Coutinho (1999), foi o primeiro direito social reconhecido na modernidade de forma positiva. Após esse evento, outros direitos foram conquistados, como saúde, habitação e previdência pública.

O movimento para uma política pública deve estar associado à gestão financeira dos recursos que concretizam as diretrizes pensadas na política. Se executado com deficiência, acarreta consequências para o desenvolvimento e atendimento dos beneficiários (Braga, 2011). Logo, o financiamento da educação pública deve ser visualizado como um fator importante no que tange as políticas públicas voltadas à educação, pois sem os recursos do fundo não há como mensurar como a classe mais carente terá assegurada o seu direito constitucional. 
3.2 As principais fontes para o financiamento da educação básica a partir da constituição federal de 1988: salário educação e a vinculação e sub vinculação de recursos experiência do Fundef ao Fundeb.

O instrumento da vinculação assegura os percentuais mínimos de dispêndio para a educação, sendo esse o mecanismo utilizado como garantia de manter recursos, prioritariamente, à educação. Nesse sentido, a vinculação de recursos destinado esteve presente na constituição de 1934, sendo revogada em alguns períodos, como na constituição de 1937 e 1967.

A esse respeito, Menezes (2008), em A vinculação constitucional de recursos para a educação: Os (des)caminhos do ordenamento constitucional, explica-nos que nos tempos do Ato Institucional 05 (AI-05), de 13 de dezembro 1968, que deu ao regime militar poderes absolutos, apenas os municípios mantiveram a vinculação de recursos destinados à educação, já que o governo central e os estaduais não tinham mais a obrigação de vincular seus recursos para a educação.

Com o processo de redemocratização do país, a luta por uma escola pública com melhores condições tomou proporções em vários setores da sociedade, e como resultado aconteceu a aprovação da Emenda Constitucional n 24 , de 1983 , de autoria do senador João Calmon, que visou resgatar a vinculação constitucional, determinando a aplicação mínima de 13\% da União e aos estados, Distrito Federal e municípios, 25\% da receita resultante de impostos, para a manutenção e desenvolvimento do ensino.

Segundo Menezes (2008) os debates que ensejaram a Emenda Calmonde 1983, encontraram na vinculação constitucional de recursos, espaço propício para a construção paradigmática da relação direta entre financiamento da educação e a universalização e democratização do ensino no país. Assim, a vinculação - ao estabelecer limites para gastos com a educação - apresentou aportes de recursos para a educação pública, firmou a sua importância como política pública.

Pinto (2000) ressalta que, nos momentos em que as Cartas Constitucionais deixaram de determinar um percentual mínimo de investimento na educação, ocorreu maior escassez de recursos para a área. Logo, mesmo a vinculação constitucional de parte da receita de impostos ser considerada uma conquista fundamental, porque garantiu um mínimo de recurso para a educação, somente ela não pode solucionar todos os problemas das políticas de financiamento da educação pública para o país.Assim, Pinto $(2019$, p.26) diz que o grande mérito da vinculação de recursos foi assegurar que o setor se beneficiasse do ciclo de crescimento econômico que bafejou o país, em especial no período de 2006 a 2015, bem como garantir uma relativa estabilidade dos gastos públicos em relação ao PIB.

A fim de combater essa problemática (associada às limitações orçamentárias de um grande número de instâncias subnacionais), o governo federal, em 1998, alicerçou e alavancou o Fundef no País, substituído, posteriormente, pelo Fundeb (Menezes, 2008).

Em outras palavras, o Fundef foi o primeiro arranjo redistributivo, segundo Cavalcanti (2019), dos recursos financeiros da educação pública, usado exclusivamente para o ensino fundamental, objetivava alcançar progressos no ensino fundamental, como o aumento do número de matrículas que visava à universalização.

O Fundeb substituiu o Fundef, com um alcance maior que o fundo anterior, pois o Fundeb atingiria toda a educação básica. Este fundo seguia as mesmas características do anterior, distribuindo os recursos de acordo com a proporção de matrículas nas redes estaduais e o Valor-aluno-ano (VAA).

Ressaltamos que Fundeb corresponde a 27 fundos contábeis estaduais em que tributos federais, estaduais e municipais, cada fundo estadual é composto pelo respectivo montante desta cesta de tributos, podendo ser utilizados da educação infantil ao ensino médio em toda a federação. O recurso é redistribuído às redes municipais e estadual conforme o número ponderado de matrículas que variam conforme a etapa de ensino.

Ao que se refere ao percentual sobre os impostos, Davies (2003) nos explica que a educação estatal conta com recursos adicionais, como: salário-educação (calculado à base de 2,5\% sobre o total de remunerações pagas aos empregados 
segurados no INSS, segundo o Art. 15 da Lei 9.424/1996, que regulamentou o Fundef), convênios como os da merenda, transporte escolar, municipalização (no caso dos municípios), material didático.

Ademais, percebemos que as modificações referentes ao salário-educação aconteceram no decorrer dos anos como a Lei $n^{\circ} 10.832$, de 29/12/2003, que previa a distribuição integral da quota estadual entre o governo estadual e os municipais, com base no número de matrículas que cada um tenha no ensino fundamental, como também quanto ao repasse direto pelo FNDE (Fundo Nacional de Desenvolvimento da Educação) da parcela que cabe a cada um.

Amaral (2012) corrobora afirmando que a contribuição do salário educação teve início em 1964, tornando-se constitucional em 1988, destinando esse recurso financeiro, prioritariamente ao ensino fundamental. Após a Emenda Constitucional n 53, de 19 de dezembro de 2006, os recursos passaram a ser destinados a toda a educação básica.

Segundo Adrião \& Pinto (2006), além dos impostos e do salário educação, a lei 9.394, de 1996, em seu artigo 68, permitiu que os recursos destinados à educação viessem de contribuições sociais, incentivos fiscais ou transferências. Essa previsão, embora careça de especificidade e peque pela generalidade, apresenta-se como indicador para ampliação dos investimentos em educação, se for considerado que os valores per capita praticados no Brasil. Porém, diante desse cenário, entendemos ainda que são insuficientes para assegurar um ensino de qualidade (Adrião \& Pinto, 2006).

\section{Discussões}

As discussões serão acerca do financiamento da educação, outrora, era um terreno pouco explorado pelos pesquisadores. A partir da Emenda Constitucional nº14/1996 que o Fundef começou a participar dos debates sobre a temática, sobretudo no universo acadêmico e no âmbito das políticas públicas voltada para educação (Peroni, 2003).

$\mathrm{Na}$ atualidade, muitas pesquisas foram desenvolvidas no campo do financiamento da educação básica, evidenciando a importância do atual Fundeb, tanto no que se refere a sua formulação, quanto sua implementação e fiscalização.

A partir dessa observação, para dar início à revisão da literatura de nossa pesquisa, foram identificadas teses e dissertações que têm o financiamento da educação como tema central de suas pesquisas, e compõem a base de dados da Biblioteca Digital Brasileira de Teses e Dissertações (BDTD). Nesse contexto, a BDTD integra os sistemas de informação de teses e dissertações existentes nas instituições de ensino e pesquisa brasileiras, como também estimula o registro e a publicação em meio eletrônico.

As pesquisas fazem parte dos programas de pós-graduação e a área em que há mais presença da temática é a de educação, com $78 \%$ dos estudos (distribuídos em $71 \%$ dissertações e $29 \%$ teses. Em seguida, estão os programas de Administração, com $8 \%$ dos trabalhos. E os 14\% restante dos trabalhos estão divididos nas áreas de Economia, Ciências Contábeis, Gestão Pública, Desenvolvimento Regional, Direito e Desenvolvimento.

Para compreender alguns aspectos relacionados às pesquisas, foram analisadas também as estratégias utilizadas para o levantamento, coleta e análise de dados. Assim, compreendemos que ficaria mais evidente como se está construindo o campo de pesquisa relacionadas ao Fundeb, ainda mais quanto a política de financiamento da educação básica no Brasil.

Dentro dessa perspectiva, percebemos que a maioria dos estudos trouxe como estratégias e procedimentos metodológicos a pesquisa documental disponibilizada em sites, documentos, legislação e relatórios, juntamente com a revisão bibliográfica e entrevistas com conselheiros, professores, gestores entre outros.

Classificamos os trabalhos conforme os objetos anunciados, isto é, em cinco grupos, a saber um deles: 32,5\% referentes aos Conselhos de Acompanhamento e Controle Social: CACS, que em sua maioria busca entender os limites e atuação do Conselho em determinados municípios.

Em seguida, 20\% dos estudos encontrados na busca fazem relação do Fundeb com os impactos nos entes federados. Percebemos ainda que a valorização do profissional do magistério e sua remuneração, a partir do Fundeb, aparecem com 15\% 
dos trabalhos. Ademais, a Educação Infantil é tema de pesquisa, ou seja, em 12,5\%. Além disso, observou-se que o estudo de caso do Fundeb, em um determinado município, discutiu a formulação, a implementação e a análise do Fundeb, em 10,0\% dos trabalhos.

\subsection{As pesquisas com o foco no CACs Fundeb}

O funcionamento do CACS é um tema do financiamento da educação muito debatido entre os pesquisadores que investigam o fundo de manutenção da educação no Brasil. Em sua maioria, tem um ponto de consenso que é a pouca eficiência dos conselhos municipais que devem fiscalizar onde é empregado o valor disponibilizado pelo Fundeb.

Outros consensos sobre o CACS Fundeb são: quanto a participação/atuação dos atores no processo de fiscalização dos recursos recebidos que são limitados por fatores, como a inexistência de uma política de formação; os conselheiros apenas cumprem as funções para regularização das exigências legais referentes aos recursos do Fundeb, não se apropriando de discussões sobre a importância de investimento em áreas fundamentais; e o funcionamento do CACS, ou seja, geralmente é restrito a reuniões com conselheiros para prestação de contas dos repasses do fundo.

Como pontos de controvérsia, verifica-se a contradição do Controle Social e o frágil processo de democratização. Estudos desenvolvidos por Gonçalves, (2015) e Caldeira (2016), apontam que a inexistência funcional do CACS, e outros, concluem que há funcionalidade, porém precisam de ajustes. Logo, há a atuação dos conselheiros de forma autoritária/patrimonialista/burocrática, da parte de alguns gestores, em que o CACS, como importante instrumento de controle social, abrange toda a comunidade escolar (Silva, 2013).

Além disso, observa-se a atuação dos conselheiros, no que tange a experiência de integração do CACS e o Conselho Municipal de Educação (Freire, 2016), a função real do CACS, ainda mais se a função principal é ser mais atuante como fiscalizador dos recursos recebidos para a educação básica ou ser mais presente nos debates do uso com qualidade das verbas destinadas à educação (Batista, 2017).

A partir desse cenário, compreendemos que os elementos precisam de maior esclarecimento para uma sociedade que se interessa em compreender esse processo como os limites e possibilidades, ainda mais quanto a organização administrativa dos Conselhos nos municípios e como seria a capacitação dos conselheiros para o exercício de suas funções que tantos os estudos revelam importante (Andrade, 2016), ou seja, prevendo conhecimentos multidisciplinares e uma formação técnicapolítica-crítica (Aquino, 2019).

A precária formação inicial e continuada dos conselheiros é um fator. Conforme Andrade (2016), limita a atuação dos conselheiros. O autor diz que alguns conselhos conseguem fazer seu papel, mesmo com inconsistências, com maior responsabilidade e compromisso fiscalizador, buscando uma atuação que aumente a legitimidade do processo. Outros precisam de formação específica para conseguirem mais independência aos acessos das informações de gestão financeira.

\subsection{Relação entre os entes federados e o Fundeb, e seus impactos no contexto de políticas de financiamento}

Autores como Mendes (2012) e Borges (2007) estudam o financiamento da educação a partir do contexto Fundef, seguindo com o Fundeb. Ambos os fundos apresentam aspectos positivos e negativos. Nesse sentido, o Fundeb aprimorou o fundo anterior quando permitiu uma maior participação da sociedade civil e atingiu todos os níveis da educação básica, porém ainda tem como aspecto negativo o valor mínimo por aluno, porque não garantiu a equidade entre as etapas de ensino (Mendes, 2012).

Por sua vez, Borges analisou o Fundef e seus problemas, limitações e avanços, partindo em seguida para a análise do Fundeb como a nova política de financiamento. Logo, explorou os efeitos e impactos financeiros redistributivo no âmbito das três esferas federativas dessa última política pública. 
Magro (2014) traz à tona a problemática dos municípios, ainda mais quanto ao Fundeb ser o único recurso, e compreendeu que eles possuem uma enorme dificuldade de aplicar de maneira satisfatória a verba destinada à educação básica. Por sua vez, aqueles que possuem maior arrecadação tributária não dependem exclusivamente dos recursos do Fundeb, porque possuem a possibilidade de oferecer melhores condições estruturais para uma oferta de ensino com qualidade para a educação básica.

Nessa linha de pesquisa sobre a relação entre os entes federados, os estudos de Lins (2014) e Gomes (2014), fundamentados a partir do repasse do Fundeb, avaliaram como está o desempenho escolar dos estudantes e a divisão de responsabilidade entre os entes federados. Os estudos mostraram o desempenho escolar e um certo crescimento no $5^{\circ}$ ano, porém avaliado somente a partir do IDEB, sem outras variantes.Ademais, nas relações entre entes federados, percebemos pelos estudos deles que o correram poucas variações, a maior foi em relação à oferta de matrículas para os anos finais do ensino fundamental, isto em alguns entes da federação.

Queiroz (2011) investigou a existência de compatibilidade entre as normas do Fundeb e da Lei de Responsabilidade Fiscal (LRF), usando métodos de contabilidade para delinear sua pesquisa e concluiu que a receita do Fundeb é significativa para os municípios estudados, ainda maisquanto a incompatibilidade entre Fundeb e LRF.

Assim, quanto a análise das pesquisas que fizeram relação entre os entes federados e o Fundeb e seus impactos no contexto de políticas de financiamento, percebe-se que há de consenso que tanto o Fundef quanto o Fundeb apresentam aspectos negativos e positivos na sua formulação. No Fundef, os aspectos negativos foram: falta de investimentos/recursos novos e o atendimento somente a educação fundamental. De aspectos positivos destaca-se mais investimento para o ensino fundamental, bem como mais alunos matriculados nessa etapa.

Por sua vez, no Fundeb, os aspectos positivos que todos concordam foi a abrangência do fundo e o atendimento a todas as modalidades, porém é possível verificar que o Fundeb surgiu com a responsabilidade de reduzir as desigualdades sociais, mas não atingiu a meta em sua totalidade (Lins, 2012; Borges, 2007; SILVA, 2018).

Autores como Borges (2007) vêem o Fundeb como uma política de inclusão sócio educacional, com efeitos financeiros claramente delineados, porém nem todos estão de acordo. Outros autores, como Magro (2014), justificam que existem lacunas, como, por exemplo, a complementação que não chega para alguns entes que precisam de complementação, ou ainda, como uma falha na política de fundos.

Ademais, um ponto de controvérsia percebido após a análise dos trabalhos citados são as transferências intergovernamentais aos serviços básicos educacionais em que os autores, ora percebem como determinantes para a qualidade da educação, concluindo que já estão se encaminhando para o sucesso; ora percebem a necessidade de empregar esses recursos de maneira mais satisfatória, principalmente nos municípios que possuem o Fundeb como único recurso para educação básica.

\subsection{Valorização/Remuneração do profissional do magistério}

Nesta seção, destacaremos que um percentual dos pesquisadores se preocupou com o vencimento e a remuneração dos profissionais da educação, a partir da implementação do Fundeb (Barbosa, 2014; Oliveira, 2018; Senna, 2014).

Quando se fala nesse tema, Barbosa (2014) ressalta que somente a política de fundos é ineficiente para a promoção e valorização dos professores. Logo, podemos deduzir ser preciso mais investimentos em formações constantes aos professores, bem como melhor suporte para que eles apliquem seus conhecimentos de maneira mais eficiente em sala de aula.

Como consenso sobre a temática "valorização e remuneração do profissional de magistério", percebe-se que, apesar de melhoras no vencimento dos docentes da federação, não é possível afirmar que todos os entes pagam salário próximo do ideal aos seus profissionais. Muitos ainda precisam de um plano de cargos e carreira mais eficiente, pois a valorização desse profissional ainda não atingiu a meta almejada pelo fundo (Senna, 2014; Oliveira, 2018; Ferreira, 2014). Em suma, esse plano 
de cargos e carreira necessita de mais viabilidade em vários entes da federação, como, por exemplo, no Pará, para que possa haver aumentos reais, através de progressões e titulações recorrentes (Carvalho, 2012).

No Novo Fundeb também se busca o aprimoramento da valorização e remuneração do profissional da educação, pois todos os atores envolvidos entendem que para uma educação de qualidade, ele precisa ser melhor atendido, ter uma melhor remuneração e uma escola que proporcione recursos não só áudio e visual, como também estrutural; tudo para que favoreça-se um bom aprendizado.

\subsection{O Fundeb e a Educação Infantil}

Outra área de pesquisa é referente ao nível da Educação Infantil, já que a partir do FUNDEB a etapa passou a fazer parte da educação básica, tendo assim uma parte dos recursos do fundo destinado a elas. O ponto de consenso dos estudos é que com a entrada da educação infantil para a educação básica, o número de matrículas aumentou consideravelmente com criação de creches e pré-escola na rede pública, porém, apesar do aumento, ainda há carência de vagas em algumas localidades, principalmente quando se trata de creche, que atende as crianças de 0 a 3 anos (Santos, 2012; Lima, 2015; Abdalla, 2016).

Um ponto de discussão no atual fundo que também foi pauta para discussões na proposta para o Novo Fundeb é o repasse de recursos para atendimento em creches conveniadas em toda a federação, já que para muitos envolvidos no processo de formulação da proposta, os recursos do novo fundo precisam atender exclusivamente o ensino público. A esse respeito, Neiverth (2009) afirma que o atendimento em creche conveniada vai ao encontro dos interesses do capitalismo, já que trabalhadores necessitam de lugares para deixar seus filhos. Logo, a partir desse ponto justifica-se dizer que a educação infantil tem um fim mais destinado à política assistencialista que educacional.

Com efeito, percebemos que as pesquisas se concentram, em sua maioria, no atendimento nas creches, com o público de 0 a 3 anos, ficando de fora e passível de mais investigação o segmento de 4 e 5 anos, que também é compreendido como Educação Infantil.

Abdalla (2016) diz que, após o Fundeb, essa etapa da educação foi mais valorizada, e cresceu a preocupação com o número de matrícula nas instituições públicas, privadas e o repasse de verbas para elas. Os apontamentos de Santos (2012) revelaram que a implantação do Fundeb como política de financiamento para Educação infantil, em Itabuna, possibilitou mais investimento e atendimento na esfera pública desse nível de ensino, ou seja, com uma política de melhorias para atender as crianças de 0 a 3 anos, tornando essa etapa uma das prioridades das políticas públicas e sociais naquela região.

\subsection{Análise, composição, aplicação e resultado dos recursos em um Município}

Algumas pesquisas sobre o Fundeb giram em torno de um só Município, onde os autores analisam a composição, aplicação e resultado dos recursos desse fundo no município estudado. Ferreira (2018) fez a análise da composição e aplicação dos recursos do Fundeb em Manaus, comparando o montante recebido com os valores aplicados na educação infantil, no ensino fundamental e na educação de jovens e adultos de Manaus. O autor afirma que as ações realizadas, a partir dos recursos recebidos, podem demonstrar mudanças significativas na educação, porém não é possível afirmar que essas mudanças garantam uma educação pública de qualidade ao município, porque constatou que há falta de transparência no processo de utilização dos recursos, ainda mais quando a política de transparência se faz presente, ou seja, muitos dados e aplicações geram dúvidas aos profissionais de educação.

Assim como Ferreira, Gomes (2011) depois de analisar a aplicação do FUNDEB no período de 2007 a 2010, em Guajará-Mirim/RO, observou que, com a implementação do Fundeb, $90 \%$ das despesas pagas foram para os profissionais da educação em atividade no município de Guajará-Mirim, porém muitos aspectos negativos foram encontrados ao longo da pesquisa, como, por exemplo: falta de materiais e equipamentos para melhor qualidade das aulas e suporte ao professor e 
espaço físico escolar adequado. Logo, não se pode concluir que houve uma melhora educacional a partir da implementação do fundo.

Os estudos referentes à aplicação dos recursos do Fundeb, no município de Manaus/AM, João Pessoa e Cabedelo/PB, Guajará Mirim/RO e Viçosa/MG, chegam a um consenso que, apesar de terem ocorrido mudanças significativas na educação básica a partir da implementação do Fundeb, o ensino público e de qualidade ainda não é uma realidade. Há falta de transparência na utilização dos recursos e maior esclarecimento sobre o fundo entre os profissionais da educação, que reconhecem a sua existência, mas desconhecem o seu funcionamento (Miranda, 2010).

\subsection{Formulação, Implementação e Análise do Fundeb: atores, interesses e atuação}

Há pesquisas também voltadas para a formulação e implantação do Fundeb e como foi realizado os marcos legais do financiamento a partir do debate entre os atores e interesses envolvidos. Percebe-se que a dinâmica para o Novo Fundeb (aprovado em 2020) foi bem semelhante ao que descreveram os autores em seus estudos sobre o fundo aprovado em 2007 (Machado, 2007; Gonzaga, 2017).

A esse respeito, Gonzaga (2017) descreve em seu estudo os atores, interesses e desafios da política de financiamento por meio do Fundeb. A autora apresenta resultados, mostrando que a formulação do Fundeb teve a participação de atores que seriam os implementadores da política, representantes de instituições sem fins lucrativos, criadas para defesa dos interesses de estados e municípios. Isto é, chegando ao fim do atual ciclo do Fundeb, novos interesses e desafios, percebemos que ficou em evidência, na atualidade, a continuidade do fundo.

Nesse mesmo contexto, Machado (2007) diz que a discussão entre os atores do processo de formulação do novo fundo tem os estados defendendo a ampliação do fundo para o ensino médio e os municípios, querendo a inclusão da educação infantil como parte da educação básica, ou seja, em que ambos foram atendidos após intensos debates com intervenções da União. Também durante esse processo de formulação do Fundeb, houve mudança de posicionamento dos atores envolvidos, não por mudarem seus ideais, e sim porque buscavam um consenso mais próximo para a realidade que todos almejavam.

Nunes (2016) faz uma análise da estrutura jurídica do Fundeb, constando que há alguns aspectos no atual financiamento da educação, porque permite ambiguidades em seu desenho jurídico, ainda mais ao que se refere haver maior clareza e condições de implementação total do financiamento para a educação pública e de qualidade, como, por exemplo: fatores como disparidades regionais ainda existentes que atrasam o desenvolvimento educacional e precisam de ações mais eficazes da gestão pública.

Para o Novo Fundeb, observamos que as propostas com o olhar para essa questão de desenvolvimento regional buscaram mais equidade, porque foram amplamente estudadas, chegando à conclusão de que o Custo Aluno Qualidade (CAQ) é de fundamental importância para que essas disparidades educacionais não sejam mais uma realidade na federação.

Como base para uma política educacional mais equacionada, esses trabalhos são relevantes para que possamos entender como foi o processo de formulação do atual fundo de financiamento para educação básica.

A partir desse contexto, compreendemos ser necessário comparar como foi o aprimoramento do novo Fundeb para entender se os atores e interesses continuam os mesmos ou houve mudanças. Nisso, observamos que o Estado do Amazonas, por meio do fundo recém aprovado e agora como parte integrante da Constituição, terá mais chance de evoluir e melhor atender aos entes da federação que o compõe, contemplando as ponderações e conciliações dos recursos que assegurarão aos sistemas educacionais mais necessitados uma aprendizagem mais significativa. 


\section{Considerações Finais}

A partir do que foi observado em nossas investigações, consideramos muito importante para o processo de pesquisa entender como as políticas públicas estão relacionadas à educação e ao desenvolvimento regional, bem como acompanhar os rumos da política pública que permeiam o novo fundo de financiamento da educação pública, bem como o seu amparo jurídico e as regras sobre a distribuição dos papeis de cada ente federativo sobre o fundo.

Nesse sentido, a partir dessa revisão bibliográfica, tendo como referência o Fundeb, muitos pontos contribuem para o desenvolvimento da pesquisa, pois todos os citados se concentram na área da regulação das políticas públicas no Brasil, como, por exemplo: na estrutura legal, composição e funcionamento do Fundeb.

Após análise das pesquisas por área, percebeu-se que o CACS ainda precisa melhorar, principalmente no que diz respeito à participação da sociedade, no processo de fiscalização das ações realizadas com os recursos recebidos. Logo, entendemos que os conselheiros precisam compreender suas funções para que consigam acompanhar a sua realidade escolar. Em outras palavras, é fundamental a constante formação para os membros do conselho entenderem como se dá o processo de recebimento do recurso, investimento nas ações e prestação de contas dos recursos oriundo do fundo, tendo em vista que a atuação dos conselheiros do CACS - Fundeb - deve ir além da assinatura de atas que demonstram a legitimação do processo.

Ademais, compreendemos que a relação entre os entes federados, no contexto de política de fundos, possuem nos seus estudos diversas investigações iniciadas no Fundef e aprimorada no Fundeb; porém, no aspecto valor mínimo por aluno, observamos que esse aspecto ainda precisa ser ampliado para que os entes da federação consigam equidade em todos os níveis da educação básica, já que o Fundeb tem a responsabilidade de reduzir as desigualdades e incentivar o atendimento aos alunos de todos os níveis.

Sobre esta dimensão própria da busca de maior igualdade, Cury, (20180) chama atenção,

[...] que não se pode deixar de apontar que, relativamente à educação básica, outro fator importante e mediador da demanda de igualdade, foi o federalismo. A distribuição de competências e o consequente financiamento conhecer amidas e vindas na qual se postula um papel mais proativo da União com relação ao financiamento e uma dinâmica redistributiva de impostos de modo a subsidiar as competências dos Estados e dos Municípios (p. 1248).

Em geral, as pesquisas mostram que a relação entre os entes federados se molda e abrange vários aspectos que precisam ser revisados, periodicamente, visto que fazem parte de uma política social e fiscal, por isso, além das pesquisas na área da educação, os pesquisadores de áreas econômicas estudam a relação entre o Fundeb e outras leis que regem a área fiscal dos entes da federação.

Quanto a valorização e remuneração dos professores a partir da implementação do Fundeb, ficou evidente nas pesquisas que houve avanços relacionados à remuneração dos profissionais da educação; porém, ainda não é satisfatória em todos os entes da federação, precisando ser revistos em vários deles. Logo, interpretamos que, quando falamos em valorização do profissional da educação, compreendemos que tal aspecto vai muito além da remuneração, apesar das pesquisas acontecerem em realidades diferentes. Em suma, é possível verificar que se faz necessária uma política mais justa para uma valorização mais eficaz.

As pesquisas voltadas para a Educação Infantil mostraram melhorias com a implementação do Fundeb, principalmente na pré-escola, mas quando o olhar se volta para a creche que atende crianças de 0 a 3 anos, detectamos que ainda precisam de ajustes para um melhor atendimento a essa faixa etária. Mas, é fato que o Fundeb, quando integrou a Educação Infantil a Educação Básica, permitiu uma maior oferta de matrículas e melhor atendimento a esse nível da educação básica. 
Por conseguinte, a partir de pesquisas que estudaram o Fundeb, sua aplicação e resultados em um só município, percebemos que as ações realizadas com os recursos recebidos podem transformar a educação, positivamente, mas não é seguro afirmar que as mudanças que ocorrem em alguns entes federados são garantias de uma educação pública com qualidade.

Em outras, compreendemos que a ausência de materiais e equipamentos contribuem para uma melhor aprendizagem do aluno, com também para a estrutura física de muitas escolas, precisando de mais espaço e uma participação mais efetiva da comunidade escolar no processo de acompanhamento da gestão dos recursos, ainda mais porque entendemos que contribuiriam para um resultado mais satisfatório nos entes federados, ainda mais no que diz respeito à aplicação dos recursos do Fundeb.

É importante verificar como está a relação entre os entes federados e como a partir do Novo Fundeb, um financiamento a educação permanente, alguns aspectos podem ser revistos e aperfeiçoados para um desempenho mais favorável. Isto é, no que se refere ao CACS, como ele está inserido na proposta do Novo Fundeb, analisando-o pela perspectiva marxista nos princípios epistemológicos da análise do materialismo histórico e dialético.

É importante também investigar o caráter de cooperação entre as esferas governamentais do Novo Fundeb, como está a articulação entre Estado e sociedade, e se ele trará novos meios de ampliar o empoderamento da sociedade sobre o direito de controle, não somente de fiscalizar, mas de debater o uso qualitativo das verbas destinadas à educação do Estado do Amazonas.

As pesquisas também ampliaram o horizonte quanto ao federalismo no Brasil e as políticas públicas educacionais, no que tange a estrutura do financiamento da educação básica no Brasil e o contexto federativo. Em outros termos, apreendemos isso como um ponto de destaque que poderá contribuir com futuras pesquisas, ainda mais no cálculo do valor mínimo por aluno/ano, e se o investimento do novo fundo será eficiente para todos os entes da federação, e proporcionarem uma educação igualitária.

Outro aspecto que pode ser verificado é como ficará a partir da implementação do Novo Fundeb a parceria do poder público e escolas conveniadas que oferecem principalmente a educação infantil, uma vez que interesses de ambas as partes, estão no meio dessa discussão.

Logo, ter um olhar crítico sobre todos os aspectos que regulamentam e delimitam o financiamento da educação básica pública se torna fundamental para os pesquisadores. Paro (2000) diz que o termo qualidade, no capitalismo, é vinculada ao momento histórico e ao ponto de vista dos estudos teóricos e pesquisas em políticas públicas, assim ela precisa ser transformada em categoria permissiva de análise. Futuros estudos podem abordar como a política de financiamento do Fundef e Fundeb foram aprimoradas no Novo Fundeb que entrou em vigor em 2021, após o período de intensas discussões para a continuidade do fundo.

\section{Agradecimentos}

A Coordenação de Aperfeiçoamento de Pessoal de Nível Superior (CAPES), a Fundação de Amparo à Pesquisa do Estado do Amazonas (FAPEAM) e a Secretaria Estadual de Educação do Estado do Amazonas/SEDUC-AM, agências de fomento que apóiam o Programa de Pós-graduação em Educação da Universidade Federal do Amazonas (PPGE/UFAM).

\section{Referências}

Abdalla, P. A. (2016). O pós Fundeb no oferecimento de matrículas para a educação infantil no Estado de São Paulo. Dissertação de mestrado,Universidade Estadual Paulista.

Adrião, T. \&Pinto, J. M. (2006) Noções Gerais Sobre o Financiamento da Educação no Brasil. EccoS - Revista Científica. 8(I),23-46.

Amaral, N. (2012). Para compreender o financiamento da educação básica no Brasil. Líber Livro. 
Andrade, F. A. (2016). Controle social na política de financiamento da educação: uma análise da atuação dos conselhos do Fundeb na região metropolitana de Campina Grande, PB. Dissertação de mestrado. Universidade Federal de Pernambuco.

Aquino, J. S. (2019). Conselho de Acompanhamento e Controle Social (CACS) do Fundeb no Município de Macau/RN: Discutindo a participação dos Conselheiros. Dissertação de mestrado, Universidade Federal do Rio Grande do Norte.

Barbosa, J. L. (2014). O Vencimento e Remuneração do Magistério Público Municipal de Natal/Rn: Repercussões de Implementação do Fundeb (2007-2010). Dissertação de mestrado, Universidade Federal do Rio Grande do Norte.

Batista, J. R. (2017). CACS-FUNDEB: território de subjetividade e de possibilidades de práticas democráticas. Dissertação de mestrado, Universidade Federal de São Carlos.

Behring, E. R. \& Boschetti, I. (2009). Política Social: fundamentos e história (6a ed.), Cortez.

Bobbio, N. (2004). A Era dos direitos. Elsevier. Tradução Carlos Nelson Coutinho.

Braga, M. V. A. (2011). O Controle Social da Educação Básica Pública: A atuação dos Conselheiros do FUNDEB. Dissertação de mestrado,Universidade Federal de Brasília, Brasília, DF, Brasil.

Caldeira, R. J. (2016). Limites e possibilidades da/na gestão do conselho de acompanhamento e controle social Fundef/Fundeb Em Rondonópolis - MT. Dissertação de mestrado, Universidade Federal de Mato Grosso, Rondonópolis, MT, Brasil.

Cavalcanti, C. R. (2019). Federalismo e Financiamento da Educação Básica No Brasil: A assistência técnica e financeira da União aos entes federados subnacionais. Appris.

Coutinho, C. N. (1999). Cidadania e Modernidade. Perspectivas. 22, 41-59.

Cury, C. R. J. (2002). Direito à educação: direito à igualdade, direito à diferença. Cadernos de Pesquisa. 116, 245-262.

Cury, C. R. J. (2018). Financiamento da Educação Brasileira: do subsídio literário ao Fundeb. Educação \& Realidade. 43 (4), 1217-1252. http://dx.doi. org/10. $1590 / 2175-623684862$

Davies, N. (2003). Os recursos financeiros na LDB. Universidade e Sociedade. http://www. redefinanciamento. ufpr. br/antigo/nic3. html.

Ferreira, C. O. (2018). Fundeb Em Manaus: composição e aplicação dos recursos no Sistema Municipal de Educação na capital do Estado do Amazonas. Dissertação de mestrado. Universidade Federal do Amazonas, Manaus, AM, Brasil.

Freire, E. J. (2016). A câmara do Fundeb do conselho municipal de educação de Alta Floresta/MT: lemas e dilemas na atuação. Dissertação de mestrado,Universidade Federal de Mato Grosso, Cuiabá, MT, Brasil.

Gil, A. C. (2002). Como elaborar projeto de pesquisa. (4a ed.) São Paulo: Atlas.

Gomes, D. A. P. (2014). As consequências do Fundeb para a oferta da educação básica em dois municípios da região metropolitana de Campinas: análise das alterações na divisão de responsabilidades entre os entes federados (2005-2012). Dissertação de mestrado. Universidade Estadual de Campinas, Campinas, SP, Brasil.

Gonçalves, A. M. M. (2015). O Financiamento da Educação e o Potencial de Controle Social dos Conselhos do FUNDEB: O Caso de SINOP - MT. Dissertação de mestrado,Universidade Federal do Mato Grosso, Cuiabá, MT, Brasil.

Gonzaga, E. T. (2017). Atores, Interesses e Desafios na Formulação do Fundeb. Dissertação de mestrado. Universidade de Brasília, Planaltina, DF, Brasil. Hofling, E. M. (2001). Estado e Políticas (públicas)Sociais [online]. Caderno Cedes. 55, 30-41.

Lins, F. G. S. (2014). Recursos do FPM e Fundeb: impacto no desempenho escolar nos municípios cearenses no triênio 20072009 e 2011 . Dissertação de mestrado. Universidade Federal do Ceará, Fortaleza, CE, Brasil.

Machado, M. F. F. (2007). A proposta de FUNDEB do executivo federal: Interlocuções na formulação da política. Dissertação de mestrado, Universidade Federal do Rio Grande do Sul.

Martins, P. S. (2010). O financiamento da educação básica como política pública. Revista Brasileira de Política e Administração da Educação. 26 (3), $497-$ 514.

Magro, F. C. (2014). Federalismo, políticas educacionais e qualidade do gasto público: Uma análise do FUNDEB no Tocantins. Dissertação de mestrado, Universidade de Tocantins, Palmas, TO, Brasil.

Mendes, D. C. B. (2012). A relação entre os entes federados no financiamento da educação básica no Brasil no contexto da política de fundos (Fundef/Fundeb). Dissertação de mestrado. Universidade Federal do Pará, Belém, PA, Brasil.

Menezes, S. S. J. (2008). A vinculação constitucional de recursos para a educação:Os (des)caminhos do ordenamento constitucional. Revista HISTEDBR Online, Campinas.

Miranda, A. C. (2010). A visão dos gestores escolares sobre a influência do Fundef/Fundeb na qualidade de educação ofertada pela rede municipal de ensino de Viçosa-MG. Dissertação de mestrado. Universidade Federal de Viçosa, MG, Brasil.

Neiverth, T. (2009). A transição do financiamento das creches conveniadas em Florianópolis: entre o FUNDEB e a focalização. Dissertação de mestrado, Universidade Federal de Santa Catarina, Florianópolis-SC, Brasil. 
Research, Society and Development, v. 10, n. 11, e425101119804, 2021

(CC BY 4.0) | ISSN 2525-3409 | DOI: http://dx.doi.org/10.33448/rsd-v10i11.19804

Nunes, A. N. F. (2016). O Fundeb na prática: uma análise jurídica dos desafios para a implementação de políticas públicas no brasil. Dissertação de Mestrado, Fundação Getúlio Vargas. Escola de Direito de São Paulo, São Paulo, SP, Brasil.

Oliveira, M. L. (2018). Avaliação do Fundeb: a dependência de recursos federais e as despesas com remuneração dos profissionais do magistério nas redes de ensino municipais. Dissertação de mestrado. Universidade de Brasília, Brasília, DF, Brasil.

Paro, V. H. (1998). A gestão da educação antes às exigências de qualidade e produtividade da escola pública. In: Silva, Heron (Org). A escola cidadã no contexto da globalização. Vozes.

Peroni, V. (2003). Política Educacional Papel do Estado: no Brasil dos anos 1990. Xamã.

Piana, M. C. (2009). As políticas sociais no contexto brasileiro: natureza e desenvolvimento. In: A construção do perfil do assistente social no cenário educacional [online]. Cultura Acadêmica.

Pinto, J. M. R. (2019). A política de fundos no Brasil para o financiamento da educação e os desafios da equidade e qualidade. Propuesta Educativa. 28 (52), 24-40.

Rolim, R. M. G. (2021). A Política de Fundos no financiamento da Educação Básica: considerações acerca do fortalecimento do projeto de educação pública de qualidade. Revista Educação e Políticas em Debate. 10 (1), 54-74.

Santos, J. B. (2012). O Fundeb e a Educação Infantil no Município de Itabuna. Dissertação de mestrado, Universidade Federal Da Bahia.

Senna, R. J. (2014). A política e remuneração docente e valorização do magistério no município de Campo Grande (MS): Impactos da implantação do Fundeb (2007 - 2012). Tese de Doutorado, Universidade Federal de Mato Grosso.

Silva, J. C. F. (2018). O Fundo de Manutenção e Desenvolvimento da Educação Básica e de Valorização dos Profissionais da Educação (Fundeb) como fator de elevação das despesas previdenciárias nos municípios pernambucanos. Dissertação de mestrado. Universidade Federal de Pernambuco, Recife, PE, Brasil.

Souza, C. (2006). Políticas Públicas: uma revisão da literatura. In Revista: Sociologias, 20-45. http://www. scielo. br/pdf/soc/n16/a03n16. 